\title{
EIF3D promotes gallbladder cancer development by stabilizing GRK2 kinase and activating PI3K-AKT signaling pathway
}

Fei Zhang ${ }^{1,2,5}$, Shanshan Xiang ${ }^{1,2,5}$, Yang $\mathrm{CaO}^{1,2,5}$, Maolan $\mathrm{Li}^{1,2}$, Qiang Ma ${ }^{1,2}$, Haibin Liang ${ }^{1,2}$, Huaifeng $\mathrm{Li}^{1,2}$, Yuanyuan $\mathrm{Ye}^{1,2}$, Yijian Zhang ${ }^{1,2}$, Lin Jiang ${ }^{1,2}$, Yunping Hu ${ }^{1,2}$, Jian Zhou ${ }^{1,2}$, Xuefeng Wang ${ }^{1,2}$, Yong Zhang ${ }^{1,2}$, Lei Nie ${ }^{3}$, Xiao Liang ${ }^{*, 4,6}$, Wei Gong ${ }^{*, 1,2,6}$ and Yingbin Liu ${ }^{*, 1,2,6}$

Recent evidence suggests that dysregulated elF3d expression may be critical in various genetic disorders as well as cancer. In this study, we observed that EIF3d levels increased in gallbladder cancer (GBC) samples compared with non-tumor tissue. High elF3d levels were associated with advanced tumor stage and metastasis and were correlated with poor prognosis in 92 patients with GBC. Depletion of EIF3d in GBC cell lines inhibited cell proliferation, colony formation and metastasis and induced apoptosis and cell cycle arrest in vitro and in vivo. In contrast, ectopic expression of elF3d had the opposite effects. Moreover, in this study, we revealed that a novel non-translational factor function of elF3d mediated its protumoral effects. In details, elF3d stabilizes GRK2 protein by blocking ubiquitin-mediated degradation, consequently activates PI3K/Akt signaling, and promotes GBC cell proliferation and migration. In conclusion, elF3d promotes GBC progression mainly via elF3d-GRK2-AKT axis and it may be used as a prognostic factor. The therapeutic targeting of elF3d-GRK2 axis may be a potential treatment approach for GBC.

Cell Death and Disease (2017) 8, e2868; doi:10.1038/cddis.2017.263; published online 8 June 2017

Gallbladder cancer (GBC) is the most common biliary tract malignancy and the seventh most common gastrointestinal cancer with an incidence of 2.5 per 100000 persons according to the SEER program. ${ }^{1-3}$ Despite the relatively low incidence rate, owing to its nonspecific symptoms and highly invasive nature, most patients are at an advanced stage when they are diagnosed. The median survival time for individuals with GBC is $<1$ year. ${ }^{4}$ Most of these patients die from tumor metastasis and recurrence. Therefore, an understanding of the molecular mechanisms of GBC metastasis and recurrence is indispensable for the development of effective adjuvant therapy.

Deregulated protein synthesis and degradation contribute to cancer genesis and progression. Control of protein synthesis directs both global and selective translation of specific mRNAs, the protein products in turn promote tumor cell survival, angiogenesis, invasion and metastasis. ${ }^{5}$ Protein synthesis in eukaryotes is primarily regulated at initiation, the rate-limiting step that involves a large number of eukaryotic initiation factors (eIFs). EIF3 is the largest (650 kDa) subunit of the most complex initiation factors. Mammalian elF3 is composed of at least 13 individual subunits designated elF3a-elF3m ${ }^{6}$ and dysregulation of elF3 subunit expression correlates to cancer development and progression. ${ }^{7}$ EIF3a has been shown to be aberrantly expressed in several human cancers, including lung, breast, colon, esophagus and cervical cancers, and its depletion by antisense cDNA reversed the malignant phenotype in human cancer. ${ }^{8-12}$ EIF3b has been reported to be overexpressed in colon cancer cells and related to human bladder and prostate cancer prognosis ${ }^{13,14}$ Overexpression of a truncated elF3e mutant caused malignant transformation of mammary epithelial cells both in vitro and in vivo. ${ }^{15}$ EIF3h is frequently amplified in breast, prostate cancer and non-small cell lung cancer alone with the adjacent MYC pro-oncogene and its overexpression promotes cancer cell growth. ${ }^{16,17}$ Recently, elF3d is continually investigated in cancers. Sudo et al. ${ }^{18}$ first identified elF3d as one of genes involved in mesothelioma cell viability using a genome-wide small interfering RNA library. EIF3d was also associated with malignant transformation of aberrant karyotypic human embryonic stem cells. ${ }^{19}$ Most recently, a study shows elF3d is required for specialized translation initiation, regulating the target protein translation. ${ }^{20}$

However, these data fall short of implicating elF3d as a prognostic factor and molecular mechanism requirement for the maintenance or progression of human cancer. Here we show that elF3d is upregulated in GBC and strongly associated with poor patient outcome. EIF3d promotes GBC cell proliferation, migration and tumor growth in vitro and in vivo. Moreover, we revealed a novel non-translational factor function of elF3d, which inhibits specialized protein degradation. EIF3d physically interacts with the GRK2 and, as a result, abrogates the ubiquitination and degradation of GRK2 to

\footnotetext{
${ }^{1}$ Department of General Surgery, Xinhua Hospital Affiliated to Shanghai Jiao Tong University School of Medicine, Shanghai, China; ${ }^{2}$ Shanghai Research Center of Biliary Tract Disease, Shanghai, China; ${ }^{3}$ Department of Molecular and Cellular Oncology, The University of Texas MD Anderson Cancer Center, Houston, TX, USA and ${ }^{4}$ Department of General Surgery, Sir Runrun Shaw Hospital Affiliated to Zhejiang University, Hangzhou, China

${ }^{*}$ Corresponding author: Y Liu, X Liang or W Gong, Department of General Surgery, Xinhua Hospital Affiliated to Shanghai Jiao Tong University School of Medicine, Shanghai 200092, China. Tel/Fax: +86 21 25076880; E-mail: liuybphd@126.com, srrshlx@163.com or 13651819806@163.com

${ }^{5}$ These authors contributed equally to this work.

${ }^{6}$ These authors jointly directed this work.

Received 17.2.17; revised 07.5.17; accepted 08.5.17; Edited by A Stephanou
} 
a

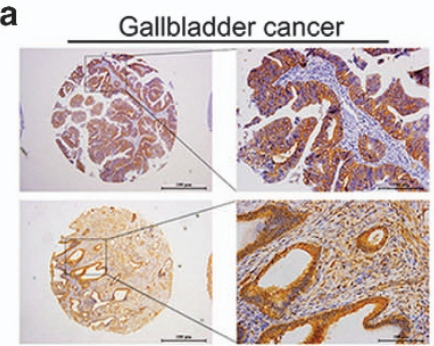
Cholelithiasis
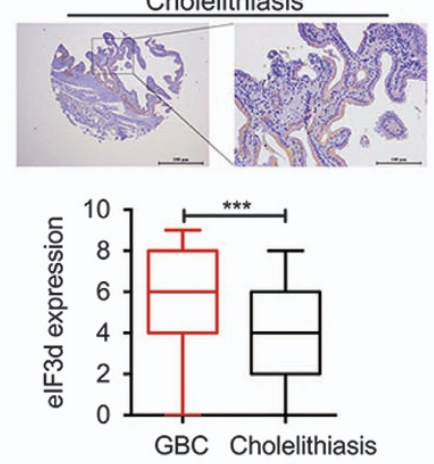

e

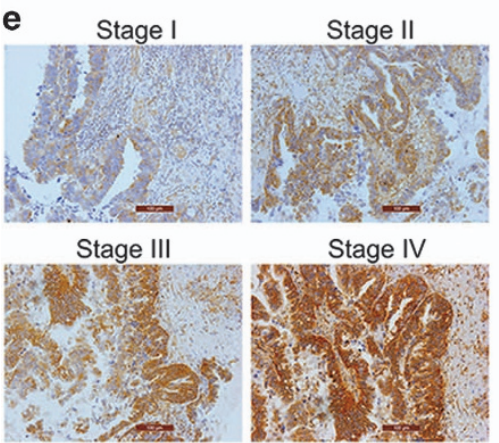

b

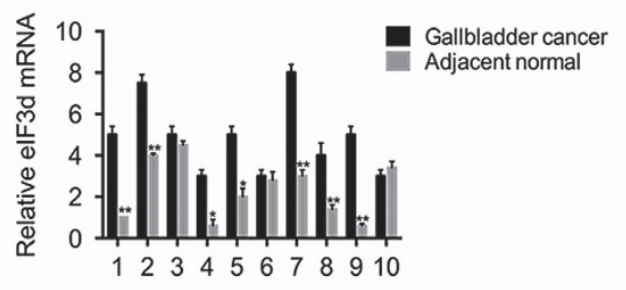

c

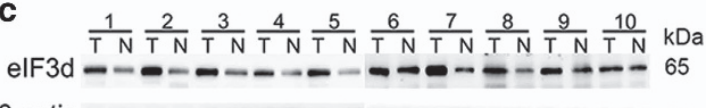

$\beta$-actin -

d

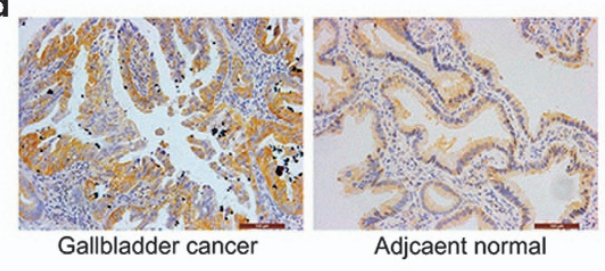

f

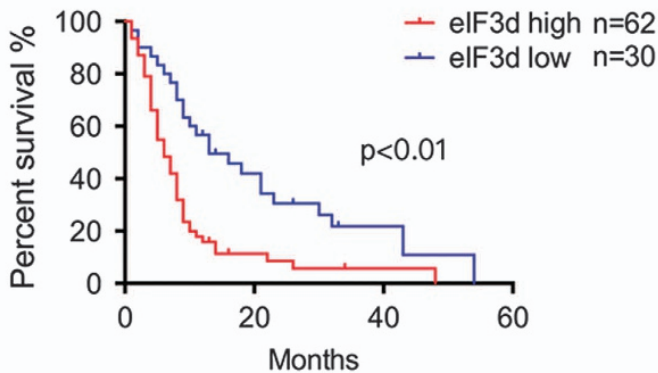

Figure 1 EIF3d is overexpressed in GBCs and correlated to GBC progression and poor survival of patients. (a) Upper panel, representative images of immunohistochemical staining of EIF3D protein expression levels in GBC (92 tumor samples) and non-tumor (cholecystitis, 103 cases) tissues. Bottom panel, quantification of EIF3D protein expression in GBC samples compared with normal tissues. (*** $P<0.001$, Mann-Whitney $t$-test). (b-d) EIF3D protein expression levels in representative primary GBC tissues (T) and their paired non-tumor tissues (N) was evaluated by qPCR (b), western blotting (c) and IHC analyses (d) $\left({ }^{*} P<0.05,{ }^{\star \star} P<0.01\right)$. (e) Representative IHC staining images of GBC patient samples with clinical stages I, II, III and IV, respectively. (d) Kaplan-Meier curve of the overall survival of GBC patients based on EIF3D expression. EIF3D high,$n=62$; EIF3D ${ }^{\text {low }}, n=30$

promote GBC progression. Taken together, our results reveal a novel mechanism by which elF3d control the target protein stability via posttranslational mechanism.

\section{Result}

EIF3D is aberrantly expressed in GBC and correlates with poor survival in GBC patients. Recently, some studies have reported that elF3d was involved in the development and progression of several types cancer cells. ${ }^{21,22}$ To explore whether elF3d expression level is associated with pathological features and disease progress, we determined elF3d expression levels in the gallbladder tumor and non-tumor tissues by IHC staining. The expression of elF3d levels was increased significantly in 92 human tumor samples as compared with the 103 cholecystitis gallbladder epithelial tissues (Figure 1a). Furthermore, the mRNA and protein expression levels of elF3d were measured in 10 pairs of human GBC specimens and their matched normal tissues by qRT-PCR, western blot and IHC. The expression level of elF3d was significantly higher in tumor tissues than that in their non-tumor counterparts (Figures $1 b-d$ ). To further investigate the correlation of elF3d with GBC progress, we analyze the elF3d expression in 92 GBCs. A clinicopathologic association study in GBCs demonstrated that overexpression of elF3d was significantly associated with advanced clinical stage (Figure 1e), and lymph node and liver metastasis (Table 1). These data imply that elF3d may have an important role in GBC progression and metastasis. The Kaplan-Meier analysis on overall survival versus elF3d expression in 92 patients was shown in Figure 1f. The prognosis for patients with low elF3d expression was significantly better than that for patients with higher elF3d expression $(P<0.01)$.

EIF3d promotes GBC cell growth. To explore the role of elF3d in the progression of $\mathrm{GBC}$, we first detected the endogenous expression of elF3d in six GBC cell lines. EIF3d 
Table 1 Correlation of elF3d expression with clinicopathological features in GBC specimens

\begin{tabular}{|c|c|c|c|c|}
\hline \multirow[t]{2}{*}{ Characteristic } & \multicolumn{3}{|c|}{$\begin{array}{l}\text { Patient \# of EIF3D } \\
\text { expression score }\end{array}$} & \multirow[t]{2}{*}{$P$-value } \\
\hline & Total & $-/+$ & $++/+++$ & \\
\hline Age & & & & 0.296 \\
\hline$<64$ & 44 & 12 & 32 & \\
\hline$\geq 64$ & 48 & 18 & 30 & \\
\hline Gender & & & & 0.675 \\
\hline Male & 31 & 11 & 20 & \\
\hline Female & 61 & 19 & 42 & \\
\hline Tumor differentiation & & & & 0.236 \\
\hline Well/moderate & 35 & 14 & 21 & \\
\hline Poor & 57 & 16 & 41 & \\
\hline TNM stage (AJCC) & & & & $<0.001$ \\
\hline I/II & 39 & 30 & 9 & \\
\hline $\mathrm{III} / \mathrm{IV}$ & 63 & 10 & 53 & \\
\hline Liver metastasis & & & & $<0.001$ \\
\hline Present & 57 & 9 & 48 & \\
\hline Absent & 35 & 21 & 14 & \\
\hline Lymph node metastasis & & & & $<0.001$ \\
\hline Present & 50 & 10 & 40 & \\
\hline Absent & 32 & 20 & 12 & \\
\hline Microvascular and neural invasion & & & & 0.1683 \\
\hline Present & 56 & 17 & 39 & \\
\hline Absent & 36 & 13 & 23 & \\
\hline Total & 92 & 30 & 62 & \\
\hline
\end{tabular}

Bold values indicate $P<0.05$.

was highly expressed in NOZ and EH-GB-1 cells but weakly expressed in GBC-SD cell (Figure 2a). Interestingly, our previous study shows NOZ and EH-GB-1 cells are highly proliferative cancer cells, whereas GBC-SD cells are slowly proliferative cancer cells. ${ }^{23}$ These data suggest elF3d may contribute to regulating GBC cell proliferation. To test the hypothesis, we knocked down with shRNA against elF3d in $\mathrm{NOZ}$ and EH-GB-1, whereas ectopic overexpressed elF3d in GBC-SD cell. The efficiency of knockdown and overexpression of elF3d were evaluated by qPCR and western blot (Figures 2b, c and Supplementary Figure 1) and we chose the best one shRNA (shRNA\#2) for the following study. Meanwhile, we found silencing of elF3d did not significantly affect the expression levels of the core subunits of elF3 in GBC cells (Supplementary Figure 2).

Next, we examined the biological effects under both elF3d knockdown and overexpression conditions in GBC cells. As shown in Figure $2 d$, cell proliferation was significantly suppressed by elF3d knockdown in both NOZ and EH-GB-1 cells. In contrast, the cell proliferation was significantly enhanced by overexpression of elF3d in GBC-SD cells (Figure 2e). In addition, elF3d knockdown attenuated the colony formation capability of NOZ and EH-GB-1 cells (Figure 2f), whereas elF3d overexpression in GBC-SD cells promoted colony formation as compared with vector control cells (Figure $2 \mathrm{~g}$ ). Furthermore, knockdown of elF3d decreased the colony formation ability in soft agar assay (Figure 2h), suggesting elF3d may be required for an anchorage-independent growth of GBCs.
Silencing of elF3d leads to G0/1 cell cycle arrest and promotes apoptosis in GBC cells. To determine the mechanism by which elF3d promoted cell proliferation, we analyzed the effect of elF3d on cell cycle by flow cytometry (Figure 3a). The results showed that elF3d knockdown in the NOZ cells led to a significant reduction in the $S$ and $\mathrm{G} 2 / \mathrm{M}$ phase population, but increases G1 phase population. Consistently, elF3d knockdown reduced the expression levels of cyclin A and cyclin B1 (Figure $3 b$ ). These findings indicate that elF3d acts on the G1-S and S-G2/M checkpoint to promote the cell cycle in GBC cells. These results showed that depletion of elF3d induced cell cycle arrest. In addition, in the elF3d shRNA group, an increased cell proportion was observed in the sub-G1 population (Figure 3a). These prompted us to further examine the contribution of apoptosis to the observed growth inhibition in NOZ cells by elF3d knockdown. Flow cytometry analyses with annexin $\mathrm{V}$ and PI showed an increase in the number of early apoptotic cells and the late apoptotic cells in the elF3d knockdown cells compared with the scramble cells (Figure $3 c$ ). We examined the key cell apoptosis regulators and found that elF3d knockdown significantly reduced the protein levels of $\mathrm{Bcl}-2$ and increased the cleaved caspase-3 and poly ADP ribose polymerase (PARP) protein levels (Figure 3d). These data suggested EIF3D is involved in regulation of GBC cell cycle and apoptosis.

To verify the positive role of elF3d in gallbladder tumor progression in vivo, we performed xenograft tumor assays using elF3d knockdown stable NOZ cells. We found that elF3d knockdown significantly inhibited xenograft tumor formation and growth in nude mice (Figure 3e). We evaluated the knockdown efficiency of elF3d in transplanted tumor tissues from the mice by immunoblotting and IHC staining (Figures $3 f$ and $\mathrm{g}$ ). IHC staining with specific antibody against PCNA indicated in the elF3d depletion tumor sections that there were fewer proliferative cells, however, increased staining intensity for cleaved caspase-3 was observed, indicating significantly increased apoptosis cells in elF3d shRNA xenograft tumors (Figure $3 \mathrm{~g}$ ). Collectively, these data support our hypothesis that elF3d acted as a novel tumor-promoting molecule and positively regulates gallbladder tumor growth.

EIF3d promotes GBC cells migration in vitro and in vivo. The clinicopathologic association study in GBCs revealed that overexpression of elF3d was associated significantly with lymph node metastasis and liver metastasis (Table 1). These imply that elF3d may have a role in metastasis. To investigate the effects of elF3d on GBC cancer cell migration, the monolayer wound-healing assay and Boyden Transwell chamber assays were performed. Knockdown elF3d markedly suppressed the cell mobility and migration ability by $50-70 \%$ in the NOZ cells and EH-GB-1 cells (Figures $4 a$ and $c$ ), whereas forced expression of elF3d had reversal effect on GBC-SD cells (Figures $4 b$ and d). In addition, elF3d markedly affected GBC cells invasive ability (Supplementary Figure 3). These data were consistent with our finding that increased elF3d is significantly associated with advanced clinical stage and metastasis. The morphology of EH-GB-1 showed shuttle shape or multiple angle shape, and the multiple apophysis showed irregular shape. However, EH-GB-1 cells with elF3d knockdown inhibited cell pseudopodia formation and became oval shape, whereas 

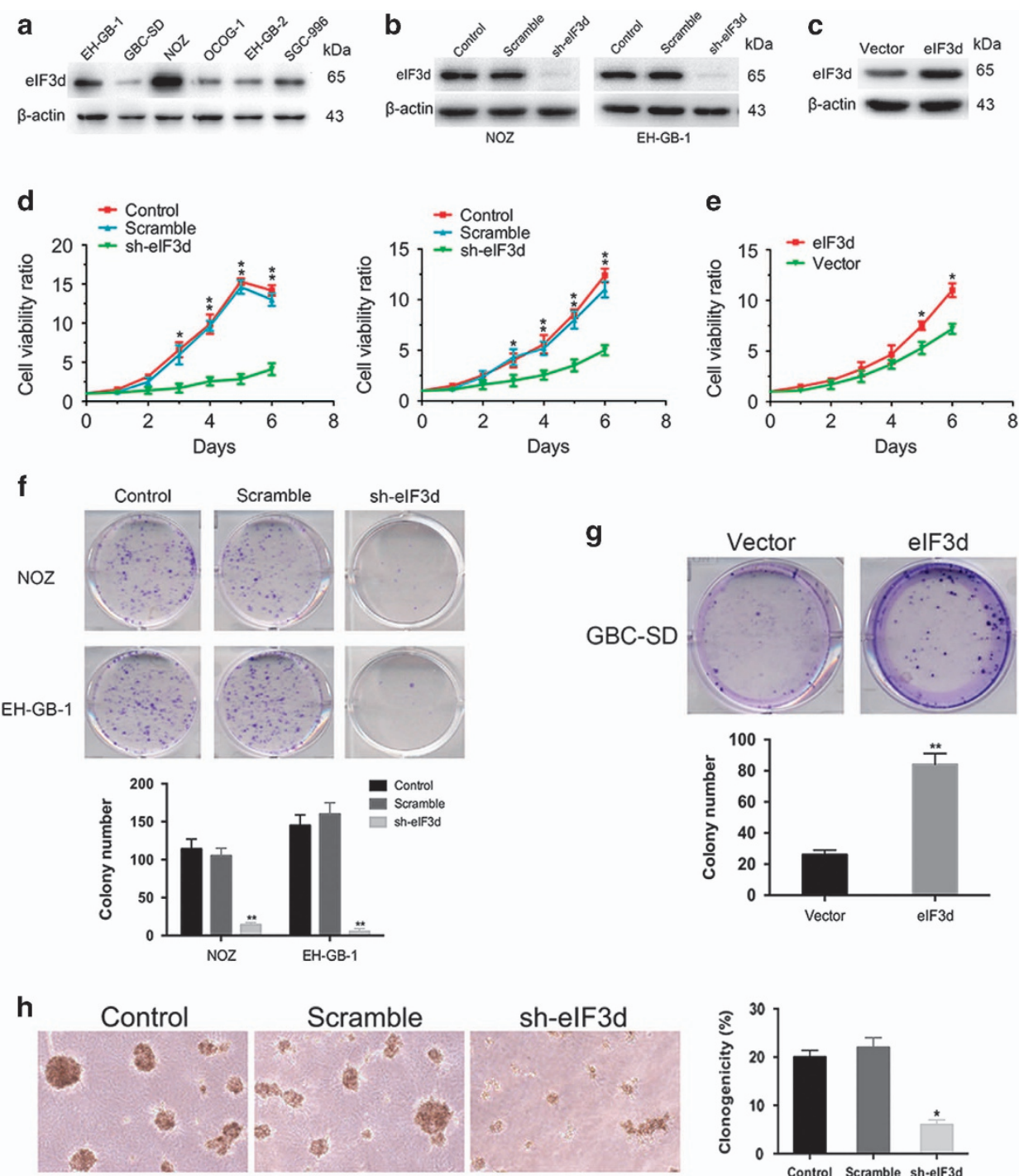

Figure 2 EIF3d promotes GBC cell growth. (a) The expression levels of elF3d protein in six human GBC cell lines. Whole-cell lysates were immunoblotted with specific antibodies against elF3d protein. (b) Lentivirus-mediated elF3d knockdown in NOZ and EH-GB-1 cells. (c) Ectopic expression of elF3d in GBC-SD cell lines. (d) Cells proliferation was inhibited in elF3d knocked down NOZ and EH-GH-1 cells. (e) Overexpression of elF3d promoted cell growth in GBC-SD cell. (f) Knockdown of elF3d suppressed colony formation in NOZ and EH-GH-1 cells. (g) Overexpression of elF3d promoted colony formation in GBC-SD cells. (h) Colony formation in soft agar assay of elF3d knockdown and control NOZ cells. Error bars indicate the mean \pm S.E. of three independent experiments. $\left({ }^{*} P<0.05,{ }^{\star \star} P<0.01\right)$

overexpression elF3d in GBC-SD cell resulted in EMT morphological changes (Figure 4e). Immunofluorescence staining showed the elF3d and cytoskeletal proteins F-actin expression in GBC cells (Figure 4f). Interestingly, compared with EH-GB-1 scramble control cells, the morphology of elF3d knockdown cells lacked thin and long pseudopods. In contrast, overexpression of elF3d in GBC-SD cell had the opposite effect. Moreover, the protein expression of the epithelial-mesenchymal transition (EMT) markers, including $\mathrm{E}$-cadherin, $\mathrm{N}$-cadherin and Vimentin, in the elF3d knockdown cells was examined by western blot. Knockdown elF3d enhanced the protein levels of E-cadherin, whereas reduced $\mathrm{N}$-cadherin and Vimentin in the NOZ cells (Figure 4g). In order to assess the contribution of elF3d to tumor metastasis in vivo, we used the animal model of experimental liver metastasis and pulmonary metastasis. We inoculated the elF3d shRNA cell and scramble cells through spleen and tail intravenous injection in immunodeficient nude mice. Tumor nodules in the liver and lung carried higher incidence in those mice inoculated with scramble cells compared with those mice injected with the elF3d knockdown cells, as revealed by gross examination and H\&E staining (Figures $4 \mathrm{~h}$ and $\mathrm{i}$ ). These data indicated that elF3d were critical for the migration of GBC cells by modulating the key EMT regulating factors.

EIF3d directly interacts with GRK2 and enhances the protein stability of GRK2 by blocking the ubiquitinmediated proteasome degradation of GRK2. To further define the molecular basis for tumor-promoting function mediated by elF3d, we performed the yeast two-hybrid assay 

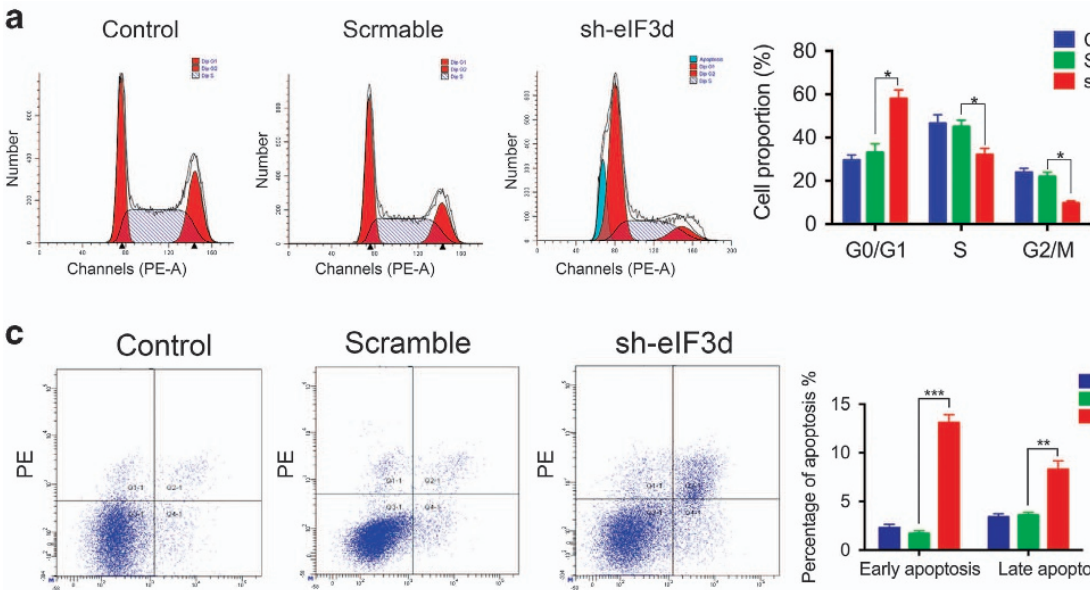

APC-A

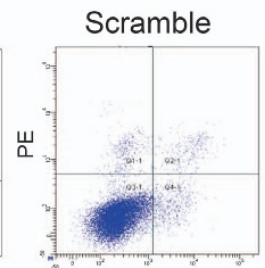

APC-A
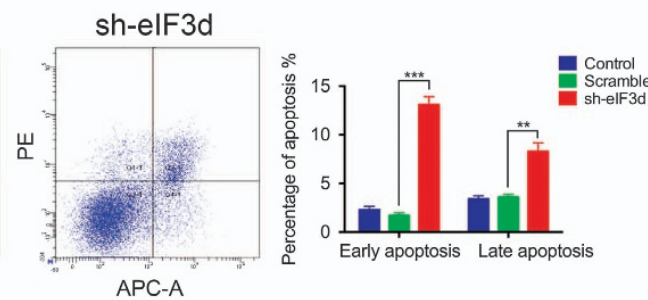

e
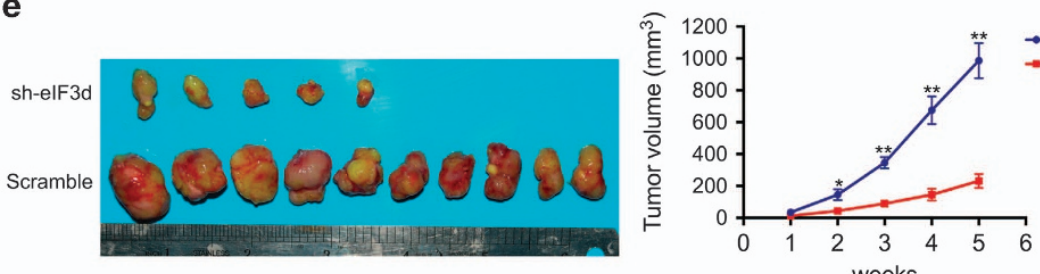
- Scramble
- sh-elF3d

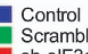

sh-elF3d
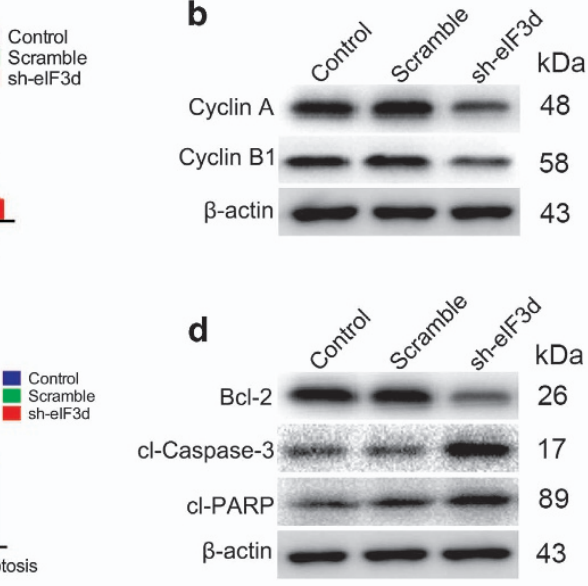

$\mathbf{f}$

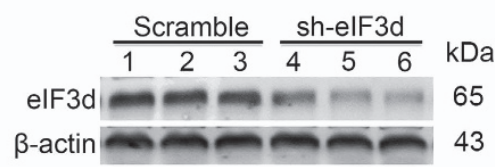

cleaved Caspase-3

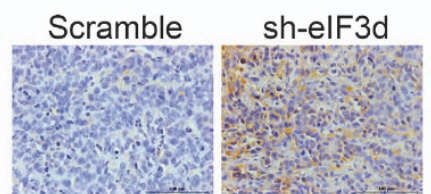

Figure 3 Silencing of elF3d leads to G0/1 cell cycle arrest and promotes apoptosis in GBC cells. (a) Flow cytometry analysis of the cell cycle of elF3d knockdown and scramble control cells. Error bars indicate the mean \pm S.E. of three independent experiments $\left({ }^{*} P<0.05\right)$. (b) The cell cycle regulator phospho-p21 (p-P21) and cyclin B1 in whole-cell lysates were detected by western blot analysis with indicated antibodies, $\beta$-actin was used as loading control. (c) Cell apoptosis was detected by flow cytometry with annexin V/PI staining. Error bars indicate the mean \pm S.E. of three independent experiments $\left({ }^{* \star} P<0.01,{ }^{* * *} P<0.001\right)$. (d) Total cell lysates were immunoblotted with antibodies against Bcl-2, cleaved caspase-3 and cleaved-PARP. (e) Tumor sizes were measured every week. The mean and S.D. were calculated from at least five independent samples. ${ }^{\star} P<0.05,{ }^{*} P<0.01$ versus control. (f) Protein expression of elF3d in GBC xenografts. (g) The expression of elF3d, PCNA and cleaved caspase-3 was detected in GBC xenografts by $\mathrm{IHC}$

with elF3d as bait and have identified six elF3d-interacting candidates (data not shown). Among those candidates, GRK2 has shown high significance of interaction with elF3d. To validate the functional interaction between elF3d and GRK2 in the cells, reciprocal co-immunoprecipitation assay was performed (Figure 5a). As expected, a positive GRK2 signal was observed in the co-immunoprecipitates pulled down by anti-elF3d-specific antibody. Moreover, elF3d was also detected in the protein pool pulled down by anti-GRK2 antibody. These results confirmed there is physical interaction between elF3d and GRK2 in GBC cell line. In the light of the interaction between elF3d and GRK2, we tested whether ectopic expression of elF3d could alter the expression of GRK2. We determined the GRK2 expression level in the elF3d knocked down cells, and found that depletion of elF3d led to a decrease of GRK2 protein level. In the other hand, ectopic expression of elF3d expression in GBC-SD cells led to an increase of GRK2 protein level (Figure 5b). These data indicated that elF3d had positive regulatory effect on GRK2 expression. The elevated protein levels could be due to either enhanced mRNA expression or protein level regulation. Our observation showed that elF3d knockdown did not affect GRK2 mRNA levels (Figure 5c). However, ablation of elF3d with shRNA enhanced the degradation of GRK2 protein, compared with scramble shRNA in NOZ cells (Figure $5 d$ ). Conversely, transfection of the elF3d expression vector in GBC-SD cells delayed the degradation of GRK2 protein (Figure 5e). Moreover, elF3d knockdown-mediated enhancement in GRK2 protein degradation was abrogated by the treatment with proteasome inhibitor, MG132 (Figure 5f). These findings suggest that ubiquitin-proteasome system is involved in the degradation of GRK2. To further confirm this hypothesis, we examined ubiquitinated GRK2 in the elF3d knockdown cells, as polyubiquitination is a signature of protein being degraded via ubiquitin-mediated proteasome system. Consistently, we found that knockdown of elF3d enhanced the polyubiquitination of the endogenous GRK2 proteins in NOZ cells (Figure $5 \mathrm{~g}$ ). Furthermore, the expression patterns of elF3d and GRK2 exhibited strong concordance in sections of human GBC tissues (Figure $5 \mathrm{~h}$ ). 
EIF3d expression significantly correlated with GRK2 expression in 92 human GBC specimens (Spearman correlation coefficient $\mathrm{R}=0.550 ; P<0.01$ ) (Table 2 ) and $6 \mathrm{GBC}$ cell lines (Spearman correlation coefficient $\mathrm{R}=1 ; P<0.01$ ) (Supplementary Figure 4). To map the region of elF3d necessary for the interaction and stabilization function with GRK2, we constructed truncation vectors of elF3d according to the strucure and sequence alignment (Figure 5i). ${ }^{20}$ As shown in
Figure 5j, GRK2 was co-precipitated with elF3d and elF3d-2 deletion mutants but not with the elF3d-1 deletion mutant. Moreover, ectopic expression of elF3d and elF3d-2 but not elF3d-1 expression in GBC-SD cells could upregulate GRK2 protein level (Figure 5k). In addition, transfection of the elF3d-2 truncation vector but not elF3d-1 truncation vector in GBC-SD cells delayed the degradation of GRK2 protein and promoted cell proliferation compared with transfection of a
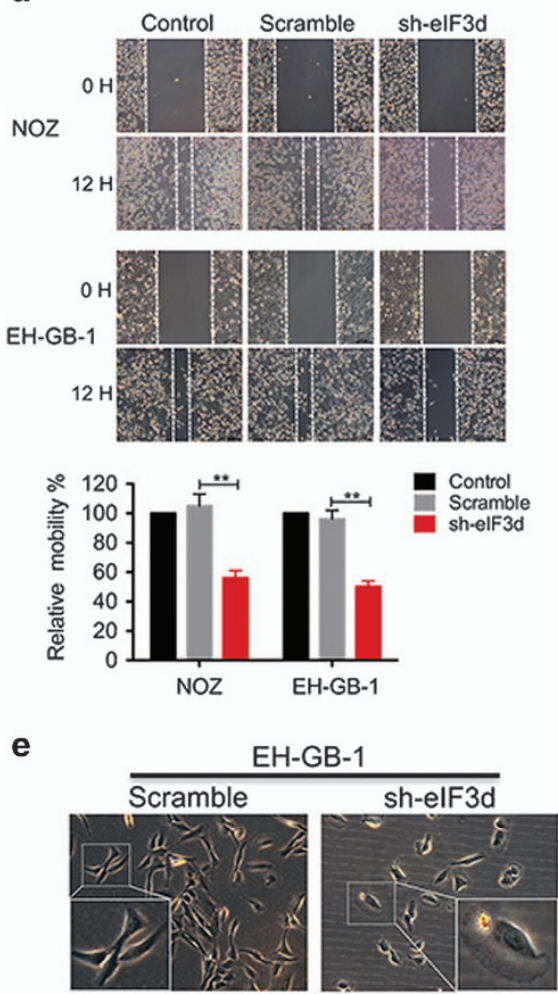

b
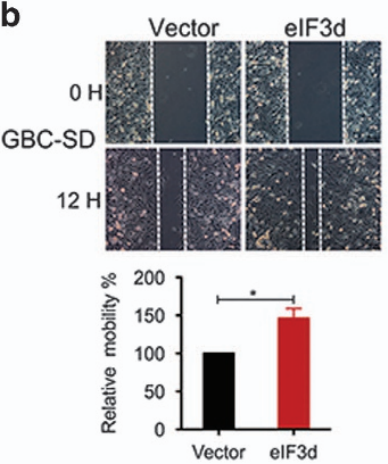

d
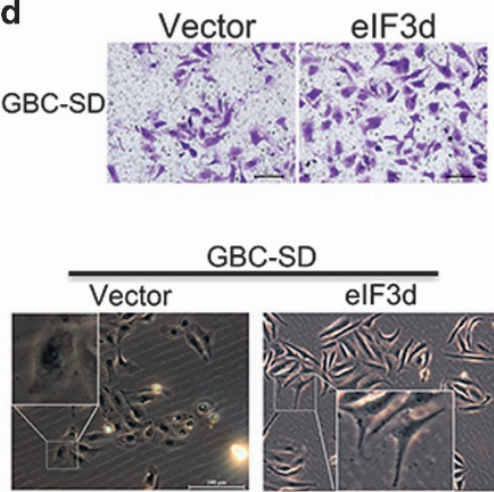
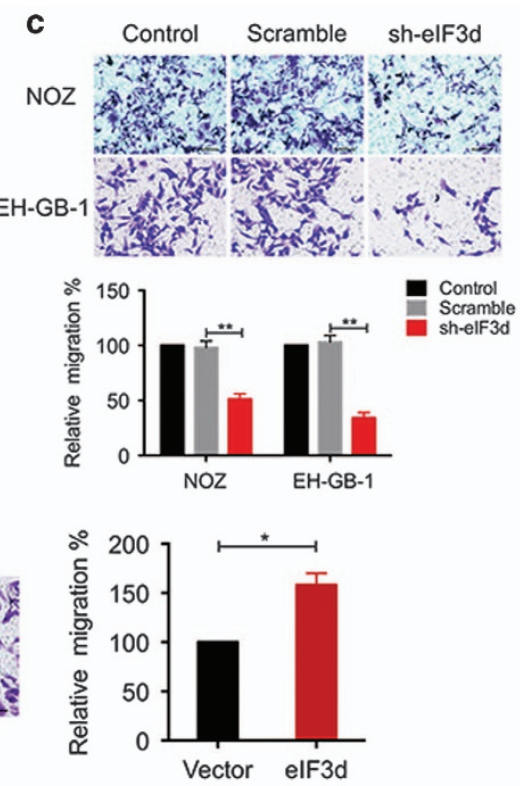

f
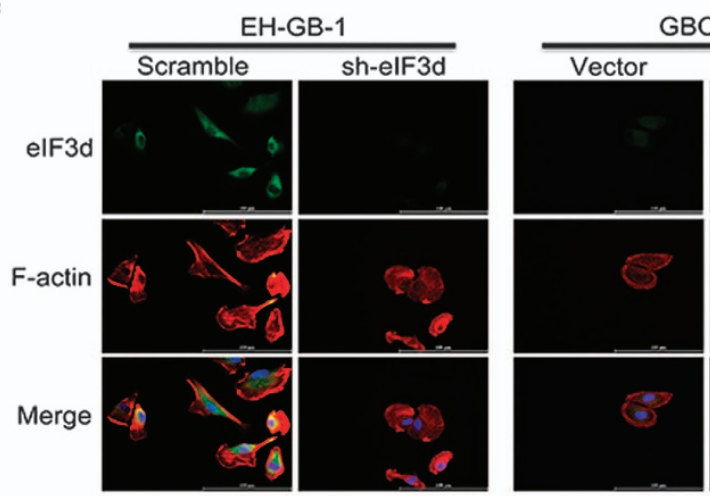

Liver

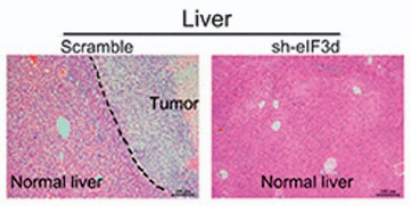

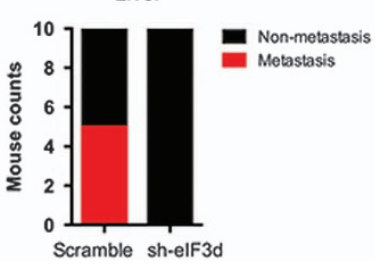

i

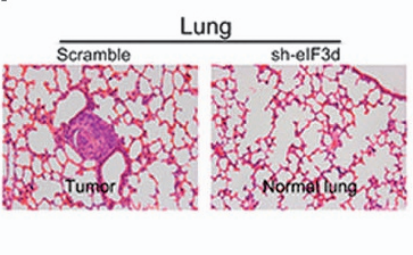

g
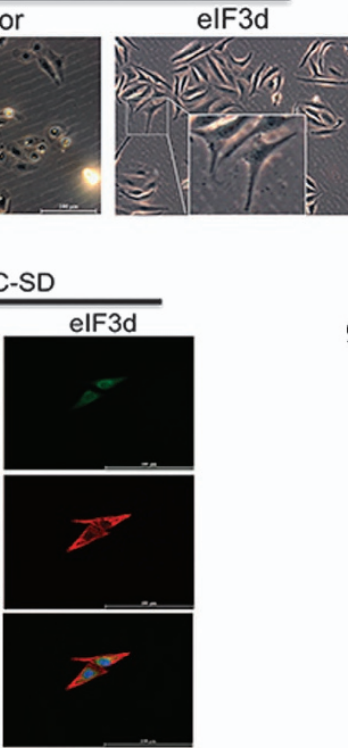

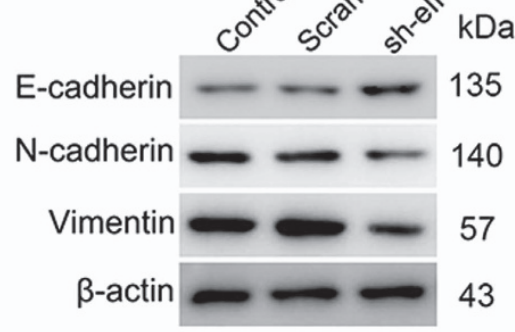

Lung

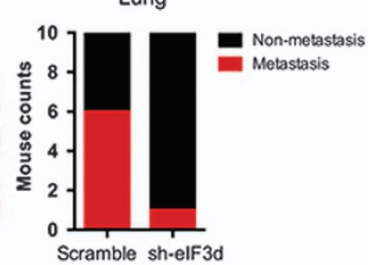


empty vector (Figures $5 \mathrm{I}$ and $\mathrm{m}$ ). Taken together, these results suggest that elF3d especially the C-terminal region of elF3d can increase GRK2 protein stability by blocking the ubiquitinproteasome-mediated degradation.

EIF3d exerts the tumor-promoting activities through GRK2-mediated activation of PI3KJAKT pathway. GRK2 is a ubiquitous member of the $G$ protein-coupled receptor kinase (GRK) family that appears to have a central, integrative role in signal transduction cascades. ${ }^{24}$ In addition to participate in the regulation and signaling of a variety of $G$ proteincoupled receptor (GPCR) activity, GRK2 has been shown to regulate a variety of proteins such as PI3K, MEK, ezrin or GIT. Consistently, splenocytes and $T$ lymphocytes isolated from $\mathrm{GRK}^{+/-}$mice display increased agonist-induced activation of ERK and PI3K/Akt pathway. ${ }^{25}$ Stable overexpression of GRK2 in breast cancer cells significantly facilitated both mitogenic (ERK1/2) and pro-survival signaling (AKT) in response to heregulin or EGF. ${ }^{26}$ Our experimental data demonstrated that ablation of elF3d can significantly decrease GRK2 protein level. Furthermore, compared with control cells, the levels of both phosphorylated PI3K and Akt were decreased in the elF3d knockdown cells, whereas their total protein levels were unaffected (Figure 6a). Thus, we speculate that elF3d regulates PI3K/AKT signaling pathway by control its upstream kinase GRK2 level. To explore the biological connection of GRK2 with the tumor-promoting function of elF3d, we examined the effect of GRK2 re-expression in elF3d knockdown stable NOZ cells on tumorigenicity. Reconstitutive expression of GRK2 can restore p-AKT expression level in the elF3d knockdown NOZ cell (Figure 6b). Furthermore, restoration of GRK2 expression level significantly rescued the hyperproliferative phenotype, colony formation and migration capacities of the elF3d knockdown NOZ cells, although it does not fully restored tumor malignancy as compared with the control group (Figures 6c-e). Consistent with these observations, treatment of the elF3d-overexpressing GBC-SD cells with GRK2 inhibitor significantly abolished the upregulated p-AKT level induced by elF3d (Figure 6f). Similarly, GRK2 inhibitor treatment attenuated the hyperproliferative status, colony forming and migration capacities in elF3doverexpressing GBC-SD cells (Figures 6g-i). Taken together, these data suggest that elF3d promotes gallbladder tumor growth and migration at least partially through regulating GRK2 activity, which in turn leads to activation of PI3K/AKT signaling pathways (Figure 6j).

\section{Discussion}

GBC is a highly invasive and rapidly proliferative cancer with a poor prognosis. $^{27}$ Therefore, elucidating the molecular mechanisms underlying GBC progression is critical for the development of new therapeutic strategies for improving the outcome of patients with advanced GBC.

Herein, we for the first time demonstrate that elF3d is involved in GBC, and this gene is highly expressed in GBCs as compared with the cholecystitis gallbladder epithelial tissues and gallbladder normal tissue adjacent tumor. The immunostaining intensity of elF3d correlates positively with the tumor clinical stage and metastasis, and elevated expression of elF3d significantly correlated with poor survival in GBC patients. Our results highly imply that elF3d may be an important biomarker and thus RNA or protein quantification of elF3d in gallbladder pathologic examination will predict prognosis of the GBC patients.

In this study, we revealed that elF3d functions as an oncoprotein. Our findings demonstrated EIF3d promotes tumorigenesis by altering cyclin $\mathrm{A}$ and cyclin $\mathrm{B} 1$, which are key regulators for cell cycle, and by antagonizing apoptosis through regulating the caspase-dependent apoptosis pathways including bcl-2, caspase-3 and PARP. In addition to its tumorigenic roles, this study also showed that elF3d enhances tumor metastasis in vitro and in vivo, indicating that overexpression of elF3d may result in metastasis-related genetic alteration in GBC cell lines. Metastasis is a multistep cellular process and the most common cause of death in GBC patients. At the molecular level, the acquisition of genetic and/ or epigenetic alterations, along with the cooperation of stromal cells, contribute to cancer metastasis. ${ }^{28}$ The underlying molecular mechanisms by which elF3d promotes metastatic potential of GBCs may, at least part, involve EMT induced by elevated elF3d in GBC. EMT is a crucial step in tumor progression and has a critical role during cancer invasion and metastasis. During this process, epithelial cells lose their properties and acquire mesenchymal phenotypes indicated by increased expression of mesenchymal-related markers, such as vimentin, and decreased expression of epithelial-related markers, such as E-cadherin. ${ }^{29-31}$ Knockdown of elF3d enhances the E-cadherin expression and suppresses the $\mathrm{N}$-cadherin and Vimentin expression. E-cadherin functions as an invasion suppressor, whereas $\mathrm{N}$-cadherin and Vimentin promote cell motility and invasion in cancers. ${ }^{32,33}$ Taken

Figure 4 EIF3d promotes cell migration and invasion in vitro and in vivo by inducing EMT. (a) Decrease of migration of NOZ (left) and EH-GB-1 (right) cells with elF3d knockdown in wound-healing assay. Relative migration rate was shown in the bar graph. (b) Ectopic expression of elF3d in GBC cells increased migration. Relative migration was shown in the bar graph. (c) Transwell migration assays of NOZ and EH-GB-1 cells expressing elF3d and scramble shRNAs. The bar graphs show the relative migration potential after 12-h culture. (d) Transwell migration assays of GBC-SD cells expressing elF3d and control cells. The graphs represent the migration rates of the cancer cells after culture on the transwell for $12 \mathrm{~h}$. Error bars indicate the mean \pm S.E. of three independent experiments $\left({ }^{\star} P<0.05\right.$, ${ }^{\star *} P<0.01$. (e) Morphologies of EH-GB-1 and GBC-SD cells were examined under a microscope. (f) Confocal images of EH-GB-1 (left) and GBC-SD (right) cells transfected with elF3d shRNA and elF3d expression vector stained for elF3d (green), F-actin (red), and DAPI (blue). (g) Effect of elF3d knockdown on epithelial and mesenchymal markers. Total cellular proteins were immunoblotted with the indicated specific antibodies against E-cadherin, $\mathrm{N}$-cadherin and Vimentin, respectively. (h) Depletion of elF3d by shRNA knockdown reduced liver metastasis. The nude mice were transplanted with $2 \times 10^{6}$ of EH-GB-1 cells (scramble and sh-elF3d) in the spleen. Representative photos of histological H\&E staining of liver metastasis were shown for each group. A bar graph summarizes the incidence of liver metastasis in the two groups. (i) Knockdown of elF3d by shRNA reduced lung metastasis. The nude mice were injected with $2 \times 10^{6}$ of EH-GB-1 cells (scramble and sh-elF3d) via the lateral tail vein. Representative photos of histological H\&E staining of lung metastasis were shown for each group. A bar graph summarizes the incidence of lung metastasis in the two groups 
together, elF3d promotes cell migration through modulating the key elements of EMT in GBCs.

Current study provides strong evidence for the oncogenic properties of elF3d, including promotion of anchorageindependent growth, inhibition of apoptosis, increase of cellular proliferation and invasion in vitro and in vivo. Accordingly, we explored the underlying mechanisms of elF3d in GBC oncogenesis, particularly the downstream signaling pathways. To define the regulatory scenario, we identify elF3d-interacting proteins by using yeast two-hybrid screening and defined for the first time that GRK2 directly interacts with elF3d.

GRK2 is a ubiquitous member of the GRK family that appears to have a central, integrative role in signal transduction cascades. GRKs participate together with arrestins in the regulation of GPCRs. ${ }^{24}$ GPCRs are founding members of the

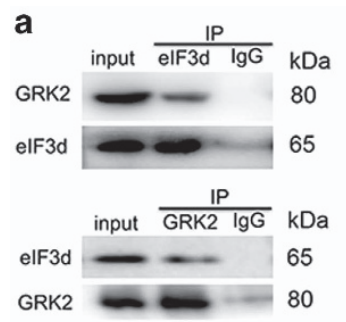

b

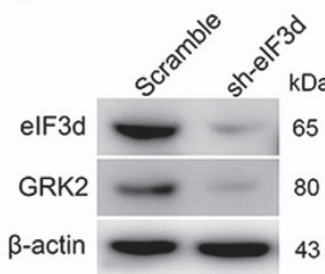

C

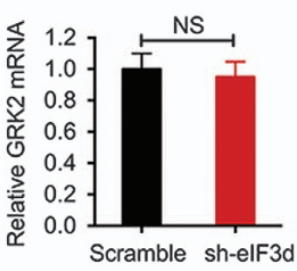

d
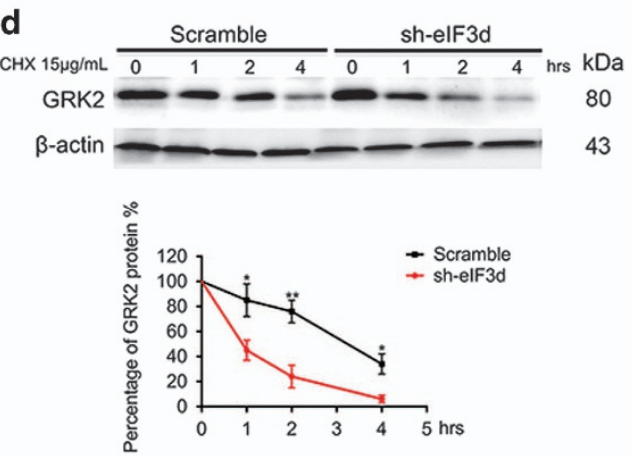

e
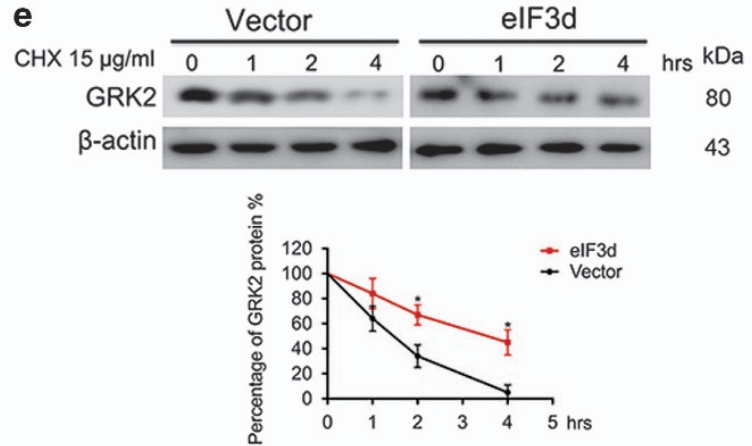

f

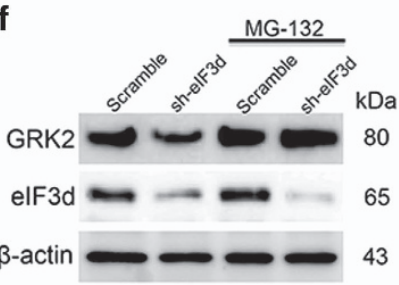

i

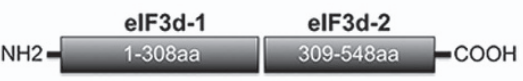

g

IP: GRK2

IB: ubiquitin

\section{3}

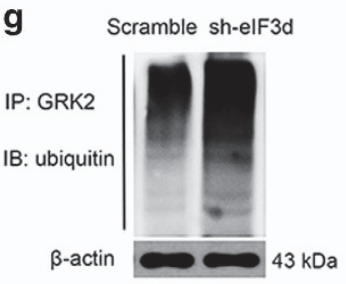

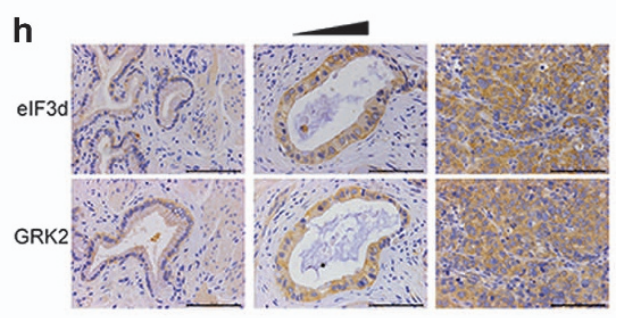

k
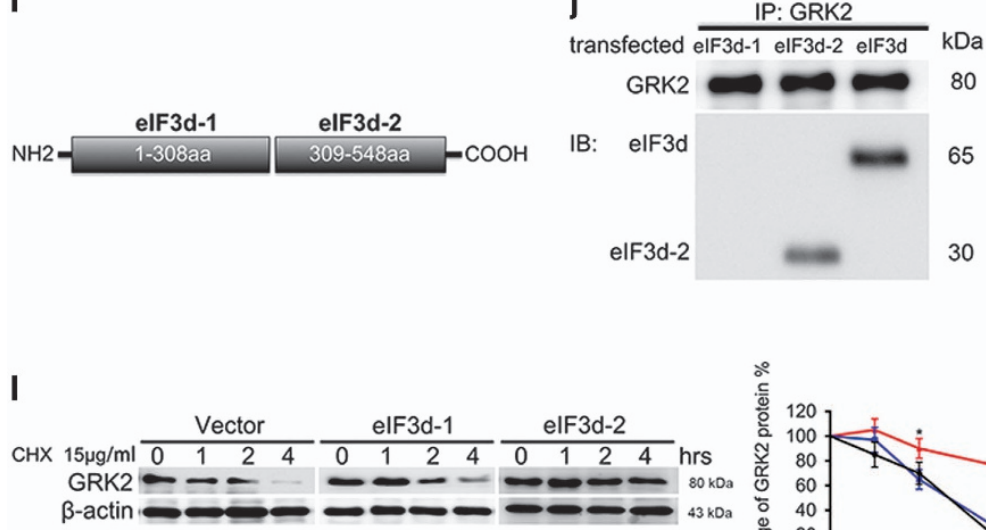

I
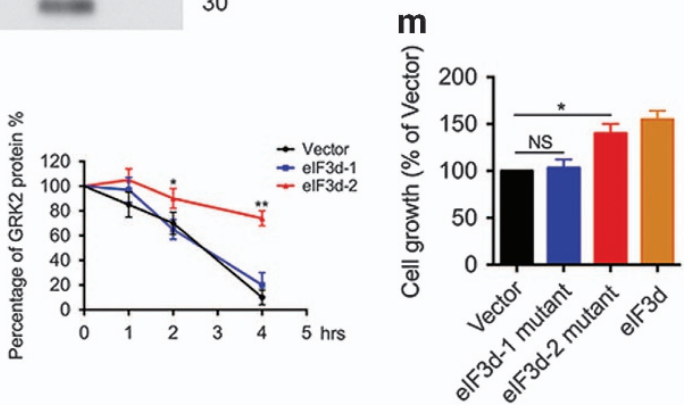
superfamily of seven transmembrane-spanning receptors that regulate physiologic and pathophysiologic processes, including initiation and progression of cancer. Overexpression and activating mutations of GPCRs are linked to tumor growth, angiogenesis and metastasis, ${ }^{34,35}$ and targeting mutated or deregulated GPCRs are promising in experimental cancer therapy. ${ }^{36,37}$ The GRKs constitute a group of protein kinases (seven members in mammals) that specifically recognize and phosphorylate agonist-activated GPCRs. GRKs are shown to be important regulator(s) specifically with respect to tumorigenesis and metastasis in many types of cancers including breast cancer, prostate cancer and pancreatic cancers. ${ }^{38,39}$ Previous studies revealed that GRK2 protein levels can be either upregulated in tissue samples of patients with granulosa cell tumors and with differentiated thyroid carcinoma, ${ }^{40}$ or downregulated in a subgroup of prostate tumors. ${ }^{41}$ In addition, GRK2 has been recently shown to establish a complex network of novel functional interactions during cell cycle progression that are critical for timely G2/M transition. ${ }^{42}$ Ho et al. $^{43}$ demonstrated that GRK2 phosphorylates Smad to inhibit activin/TGFb-mediated cell growth arrest and apoptosis in both normal and cancer liver cells. Moreover, GRK2 promotes changes in actin cytoskeleton and paxillin localization consistent with enhanced focal adhesion turnover and higher cell motility. Collectively, increased GRK2 expression facilitates migration toward fibronectin and GRK2 downregulation impairs migration. ${ }^{44}$

Table 2 Correlation between elF3d expression level and GRK2 expression level in $\mathrm{GBC}$ specimens $(\mathrm{R}=0.550, P<0.01)$

\begin{tabular}{crrrrr}
\hline & \multicolumn{5}{c}{ elF3d level } \\
\cline { 2 - 6 } & - & + & ++ & +++ & Total \\
\hline GRK2 level & & & & & \\
- & 3 & 2 & 1 & 0 & 6 \\
+ & 3 & 13 & 6 & 2 & 24 \\
++ & 0 & 5 & 16 & 7 & 28 \\
+++ & 0 & 4 & 11 & 19 & 34 \\
Total & 6 & 24 & 34 & 28 & 92 \\
\hline
\end{tabular}

Regulation of GRK2 protein stability is an important mechanism for modulating its expression levels and activity. GRK2 is rapidly degraded by the proteasome pathway, and that GRK2 ubiquitination and turnover is enhanced by $\beta_{2} A R$ activation. ${ }^{24} \mathrm{Mdm} 2$, an E3-ubiquitin ligase is involved in the control of cell growth and apoptosis, has a key role in GRK2 degradation. ${ }^{45}$ In this study, we revealed a novel nontranslational factor function of elF3d, which regulates GRK2 protein stability by blocking the ubiquitin-proteasomemediated degradation. This finding suggests that elF3d may promote GBC proliferation and migration by regulating the stability of GRK2. GRK2 is emerging as a key node in signal transduction pathways, displaying a very complex interactome. This kinase has been reported to associate with PI3K, clathrin, GIT, caveolin, ${ }^{24}$ MEK, RKIP, ${ }^{46,47}$ ERK $^{25}$ and MAPK. ${ }^{48}$ Our data further unveiled there is connection between elF3d/ GRK2 and PIK3/AKT signaling pathways in GBCs. Knockdown elF3d decreased GRK2 expression, leading to reduction of phosphorylated PI3K and AKT. Restore expression of GRK2 can rescue $\mathrm{p}-\mathrm{AKT}$ and malignant phenotype in elF3d knockdown cells. These results suggest that elF3d-GRK2 may be involved in the regulation of the PI3K/AKT signaling pathway. PI3K/Akt is a classical signaling pathway, and its activation induces cell growth, ${ }^{49}$ promotes $\mathrm{EMT}^{50}$ and stimulates Bax-mediated signaling for apoptosis progression. ${ }^{51}$ Our experimental results suggest that activation of PI3K/Akt signaling is a critically downstream event responsible for elF3d-GRK2 signal axis in cell proliferation, migration and metastasis of GBCs.

In conclusion, our study uncovered for the first time the clinical and biological significance of elF3d in GBCs. We also provide further evidence that elF3d promotes the PI3K/AKT signaling pathway by enhancing the stability of GRK2 (Figure 6j). EIF3d may be used as a prognostic biomarker for predicting prognosis of GBC patients, and pharmacological targeting elF3d-GRK2 signaling pathway may provide a potent treatment option for patients with GBCs.

\section{Materials and Methods}

Patients and clinicopathological data. Tumor tissue specimens were obtained from 92 GBC patients and 103 cholecystitis patients who had undergone

Figure 5 EIF3d interacts with and enhances the protein stability of GRK2 by reducing the ubiquitin-proteasome-mediated degradation. (a) EIF3d physically interacts with GRK2. The endogenous proteins from NOZ cells were immunoprecipitated with IgG or antibodies against elF3d and GRK2, followed by western blot analysis and $10 \%$ lysis for input. (b) Knockdown or ectopic expression of elF3d affects GRK protein levels. Immunoblotting assay was performed to detect the GRK2 protein levels in the GBC cell lines expressing elF3d or knocking-down elF3d. (c) Real-time PCR detected the GRK2 mRNA expression in the elF3d knockdown and control NOZ cell. (d) EIF3d expression level regulates stability of GRK2 protein. Knockdown of elF3d was performed in NOZ cells, followed by the treatment with cycloheximide (CHX, $15 \mathrm{mg} / \mathrm{ml})$ for various times as indicated. Whole-cell lysates were then analyzed by immunoblotting with the indicated antibodies (upper). The relative GRK2 protein level was determined using densitometry scanning (NIH ImageJ software, Bethesda, MD, USA) (down). (e) Ectopic expression of elF3d increases GRK2 stability. EIF3d expression vector or empty vector was transfected into in GBC-SD cells. Treatment of cycloheximide and immunoblotting were performed as described in $\mathrm{d}$. Error bars indicate the mean \pm S.E. of three independent experiments $\left({ }^{*} P<0.05,{ }^{* *} P<0.01\right)$. (f) The regulation of GRK2 stability by elF3d is through proteasome-mediated ubiquitination and degradation pathway. The NOZ cells were transfected with elF3d shRNA or scrambled shRNA. At $48 \mathrm{~h}$ post transfection, the cells were treated with either vehicle or MG132 (1 mg/ml) for an additional $4 \mathrm{~h}$. The whole-cell lysates were subjected to the immunoblotting with the indicated antibodies. (g) Depletion of elF3d increases ubiquitination of GRK2. The scramble and elF3d shRNA-infected cell lysates were immunoprecipitated with anti-GRK2 antibodies. The immunoprecipitates was then analyzed by immunoblotting with anti-ubiquitin (UB) or GRK2 antibodies. (h) ElF3d protein level was positively correlated to GRK2 protein level in different human GBC tissues. The representative IHC images were shown from human gallbladder primary tumor tissues. (i) Schematic representation of CDNA constructs for each elF3d deletion mutant. (j) Cell lysates were obtained from GBC-SD cells transiently transfected with elF3d and elF3d deletion mutants. The resultant lysates were immunoprecipitated and immunoblotted. (k) Immunoblotting assay was performed to detect the GRK2 protein levels in the GBC cell lines transfected with elF3d and elF3d deletion mutants. (I) EIF3d truncation vector or empty vector was transfected into in GBC-SD cells. Treatment of cycloheximide and immunoblotting were performed as described in $\mathbf{d}$. (m) GBC-SD cell transfected with empty vector, elF3d and elF3d mutant expression vector was cultured for 5 days. CCK-8 assay detected the cell viability 
a

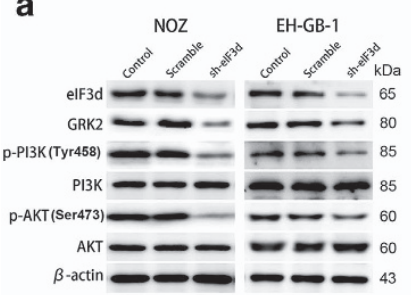

b

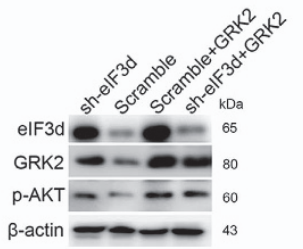

f

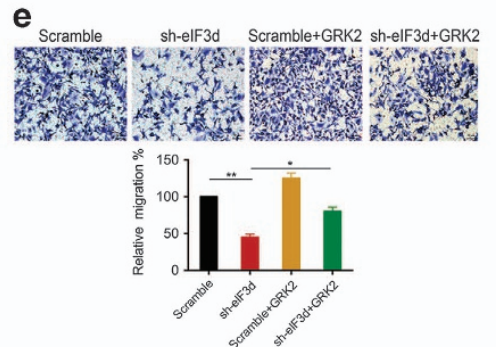

i

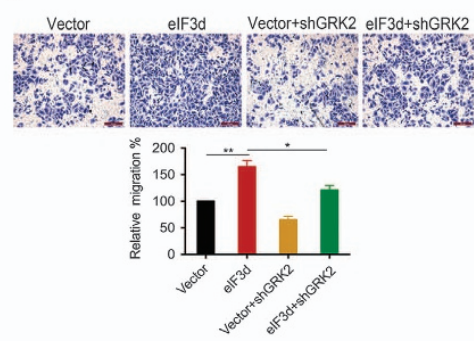

C

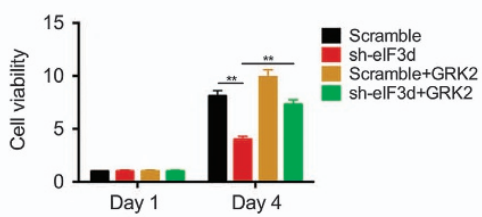

g

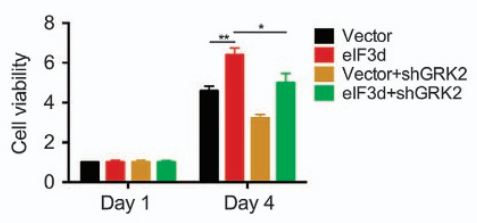

d

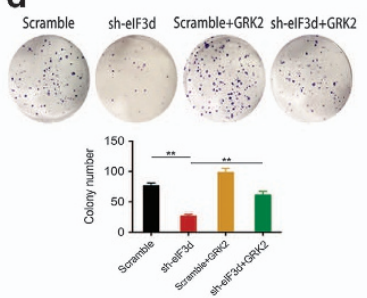

h

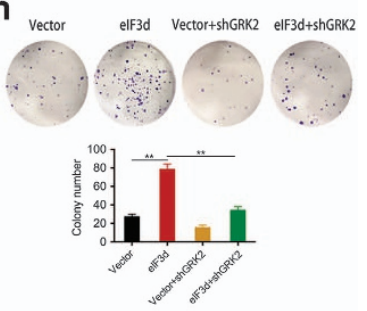

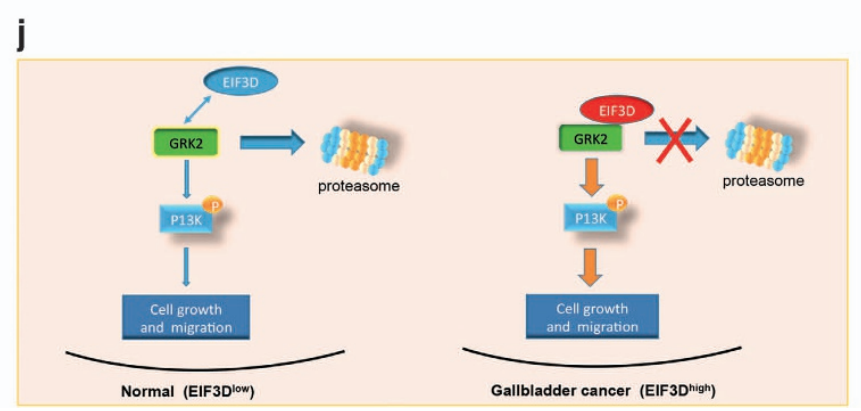

Figure 6 EIF3d exerts the tumor-promoting activities through the GRK2-mediated activation of PI3K/AKT signaling pathway. (a) The levels of phosphorylated PI3K, total PI3K, phosphorylated Akt, total Akt, elF3d, and GRK2 were detected in control, scramble and sh-elF3d cells by western blot analysis. $\beta$-Actin was used as the loading control. (b) ShRNA of elF3d and GRK2 expression vector were used to knockdown elF3d and reconstitutive express GRK2, respectively, in NOZ cells. The targeted protein levels were immunoblotted with specific antibodies as indicated. (c) Cell viability of NOZ cells expressing shRNA of elF3d and shRNA of elF3d plus GRK2 were determined by using CCK-8 assay. (d) Effects of elF3d knockdown and reconstitutive expression of GRK2 in NOZ cells on colony formation capacity. Colony numbers were shown in the bar graph. (e) Transwell assay detected the migration ability in NOZ cells transfected with scramble, sh-elF3d and sh-elF3d+GRK2. (f) Western blot analysis of GRK2 and P-AKT in GBC-SD cells expressing elF3d with or without treatment of GRK2 inhibitor methyl[(5-nitro-2-furyl)vinyl]-2-furoate at $2 \mu \mathrm{M}$ for $24 \mathrm{~h}$. Cell viability (g) and colony formation ability (h) and cell migration ability (i) were determined in GBC-S.D. cells expressing elF3d with or without treatment of GRK2 inhibitor. Error bars indicate the mean \pm S.E. of three independent experiments $\left({ }^{*} P<0.05\right.$, ${ }^{*} P<0.01$ ). (j) Proposed mechanistic scheme of elF3d stabilize GRK2 to activate PI3K/AKT signaling pathway in GBC. Overexpression of elF3d in GBC physically interacts with the GRK2 and, as a result, abrogates the ubiquitin-proteasome degradation of GRK2, which lead to activate PI3K/AKT signaling pathway, finally promote cell growth and migration

radical cholecystectomy, without any prior radiotherapy or chemotherapy, between 2008 and 2014 at the Department of General Surgery, Xinhua Hospital, School of Medicine, Shanghai Jiao Tong University, Shanghai, China. Among the 92 gallbladder adenocarcinomas, the survival information for patients was collected through phone calls. In addition, 103 patients with cholelithiasis who underwent simple cholecystectomy were included as controls. The patients provided consent for the use of tumor tissue for clinical research and the Shanghai Jiao Tong University Xinhua Hospital Ethical Committee approved the research protocol. Al diagnoses of GBC, cholelithiasis and lymph node metastasis were confirmed by histopathological examination, and all tissue samples were fixed in $4 \%$ formalin immediately after removal and were embedded in paraffin for immunohistochemical staining.

Immunohistochemical analysis of GBC tissues. Following deparaffinization and quenching of endogenous peroxidase, sections were incubated with $1 \%$ bovine serum albumin $(B S A)$ in PBS. Subsequently, the slides were treated with rabbit anti-human-elF3d (1:200, Abcam, Burlingame, CA, USA) and mouse antihuman-GRK2 (1:100, ThermoFisher, Waltham, MA, USA) antibodies followed by incubation with goat anti-rabbit and goat anti-mouse IgG antibodies. The slides were counterstained with ChemMate Hematoxylin (DakoCytomation, Kyoto, Japan) and mounted and observed under a microscope (Leica, Wetzlar, Germany). Sections were semiquantitatively scored as described previously. ${ }^{52}$
Cell lines, reagents, plasmids, transfection and lentivirus infection. Detailed descriptions of the cell lines, reagents, plasmids, transfection and lentivirus infection are available in the Supplementary Materials and Methods.

Cell viability, cell cycle, cell apoptosis, clonogenic, woundhealing, transwell migration, immunoblotting, qRT-PCR. Detailed descriptions of the cell viability, cell cycle, cell apoptosis, clonogenic, wound-healing, transwell migration, immunoblotting and qRT-PCR assay are available in the Supplementary Materials and Methods.

Immunofluorescence analysis. Transfected GBC cells were seeded onto glass slides for $48 \mathrm{~h}$. The cells were then washed once with PBS and fixed with $4 \%$ paraformaldehyde in PBS for 20 min, permeabilized with $0.1 \%$ Triton X-100 in PBS for $30 \mathrm{~min}$ at room temperature followed by blocking with $3 \% \mathrm{BSA}$ in PBS for $1 \mathrm{~h}$. The cells then were stained with anti-elF3d antibody (1:100 dilution, overnight at $4{ }^{\circ}$ C). F-actin was stained with phalloidin (Beyotime Biotechnology, Shanghai, China). Cells were mounted with DAPI Fluoromount-G media with DAPI nuclear stain. Slides were viewed with confocal microscopy (Leica).

Mouse xenograft and metastasis model. Female Balb/c nude mice (6-8 weeks of age, weighing 18-20 g) were purchased from the Shanghai Laboratory Animal Center of the Chinese Academy of Sciences (Shanghai, China). 
All mice were housed in specific pathogen-free (SPF) conditions following the guidelines of the Ethics Committee of Xinhua Hospital, School of Medicine, Shanghai Jiao Tong University. Before the experiment, mice were randomly divided into two groups (sh-elF3d and Scramble). In all, $2 \times 10^{6} \mathrm{NOZ}$ cells were injected subcutaneously into the right flank of a nude mouse. After establishment of the nude mouse xenograft model, tumor sizes were measured every week using micrometer calipers. Tumor volumes were calculated using the following formula: tumor volume $=$ width $^{2}\left(\mathrm{~mm}^{2}\right) \times$ length $(\mathrm{mm}) / 2$, where width and length were the shortest and longest diameters, respectively. All nude mice were killed after 5 weeks from the first injection and the tumors were removed for $\mathrm{IHC}$ and western blot. To induce liver and lung metastasis, nude mice were injected with $1 \times 10^{6}$ of EH-GB-1 cells (scramble and sh-elF3d) by the spleen and lateral tail vein. After 1 month, the mice were killed and the lungs and livers were removed for HE staining.

Yeast two-hybrid screening. Human elF3d cDNA fragment was cloned into pGBKT7 vector and used to screen a pACT2-human fetal liver matchmaker CDNA library in a yeast two-hybrid system (Clontech, Mountain View, CA, USA). $\beta$-Galactosidase activities were measured using o-nitrophenyl-galactoside as a substrate. Then selected positive clones were validated by sequencing.

Co-immunoprecipitation assay. Cells were washed with ice-cold phosphate-buffered saline and lysed in a lysis buffer $(50 \mathrm{mmol} / \mathrm{l}$ Tris- $\mathrm{HCl}, \mathrm{pH} 8.0$; $150 \mathrm{mmo} / / \mathrm{NaCl} ; 1 \% \mathrm{NP}-40$ ) supplemented with complete protein inhibitor cocktail (Roche, Penzberg, Germany). Cell lysates were incubated with $2 \mu \mathrm{g}$ rabbit antielF3d antibody or mouse anti-GRK2 antibody overnight at $4{ }^{\circ} \mathrm{C}$ and precipitated with $20 \mu$ l protein G-Sepharose 4 Fast flow (Thermo, Waltham, MA, USA) for $4 \mathrm{~h}$ at $4{ }^{\circ} \mathrm{C}$. The co-immunoprecipitates were washed four times with the lysis buffer and boiled for $5 \mathrm{~min}$ at $100{ }^{\circ} \mathrm{C}$ in protein loading buffer. Immunoprecipitated proteins were detected by following immunoblots.

Statistical analysis. The $\chi^{2}$ test or Fisher's exact probability test was used to compare clinicopathological features of the patients with elF3d expression. KaplanMeier plots and log-rank tests were used for survival analysis. Correlation analysis between elF3d and GRK2 expression was evaluated using Spearman correlation analysis. Statistical analysis was performed with SPSS statistical software (SPSS Inc., Chicago, IL, USA). Data were reported as the means \pm S.E. when appropriate and $P<0.05$ was considered statistically significant.

\section{Conflict of Interest}

The authors declare no conflict of interest.

Acknowledgements. This study was supported by the National Natural Science Foundation of China (nos. 81172026, 81272402, 81301816, 81172029, 91440203 and 81402403, 81672404 and 81502433), the National High Technology Research and Development Program (863 Program, no. 2012AA022606), the Foundation for Interdisciplinary Research of Shanghai Jiao Tong University (no. YG2011ZD07), the Shanghai Science and Technology Commission Intergovernmental International Cooperation Project (no. 12410705900), the Shanghai Science and Technology Commission Medical Guiding Project (no. 12401905800), the Program for Changjiang Scholars, the Natural Science Research Foundation of Shanghai Jiao Tong University School of Medicine (no. 13XJ10037), the Leading Talent program of Shanghai and Specialized Research Foundation for the PhD Program of Higher Education-Priority Development Field (no. 20130073130014), the Interdisciplinary Program of Shanghai Jiao Tong University (no. 14JCRY05), the Shanghai Rising-Star Program (no. 15QA1403100) and the China Postdoctoral Science Foundation (no. 2015 M571577).

1. Siegel RL, Miller KD, Jemal A. Cancer statistics. CA Cancer J Clin 2015; 65: 5-29.

2. Li M, Lu J, Zhang F, Li H, Zhang B, Wu X et al. Yes-associated protein 1 (YAP1) promotes human gallbladder tumor growth via activation of the AXL/MAPK pathway. Cancer Lett2014; 355: 201-209.

3. Shu YJ, Weng H, Ye YY, Hu YP, Bao RF, Cao Y et al. SPOCK1 as a potential cancer prognostic marker promotes the proliferation and metastasis of gallbladder cancer cells by activating the PI3K/AKT pathway. Mol Cancer 2015; 14: 12.

4. Li M, Zhang Z, Li X, Ye J, Wu X, Tan Z et al. Whole-exome and targeted gene sequencing of gallbladder carcinoma identifies recurrent mutations in the ErbB pathway. Nat Genet 2014; 46: 872-876.
5. Silvera D, Formenti SC, Schneider RJ. Translational control in cancer. Nat Rev Cancer 2010; 10: 254-266.

6. Browning KS, Gallie DR, Hershey JW, Hinnebusch AG, Maitra U, Merrick WC et al. Unified nomenclature for the subunits of eukaryotic initiation factor 3. Trends Biochem Sci 2001; 26: 284.

7. Lee AS, Kranzusch PJ, Cate JH. elF3 targets cell-proliferation messenger RNAs for translational activation or repression. Nature 2015; 522: 111-114.

8. Pincheira R, Chen Q, Zhang JT. Identification of a 170-kDa protein over-expressed in lung cancers. Br J Cancer 2001; 84: 1520-1527.

9. Bachmann F, Banziger R, Burger MM. Cloning of a novel protein overexpressed in human mammary carcinoma. Cancer Res 1997; 57: 988-994.

10. Haybaeck J, O'Connor T, Spilka R, Spizzo G, Ensinger C, Mikuz G et al. Overexpression of p150, a part of the large subunit of the eukaryotic translation initiation factor 3 , in colon cancer. Anticancer Res 2010; 30: 1047-1055.

11. Chen G, Burger MM. p150 overexpression in gastric carcinoma: the association with p53, apoptosis and cell proliferation. Int J Cancer 2004; 112: 393-398.

12. Dellas A, Torhorst J, Bachmann F, Banziger R, Schultheiss E, Burger MM. Expression of p150 in cervical neoplasia and its potential value in predicting survival. Cancer 1998; 83: $1376-1383$.

13. Wang Z, Chen J, Sun J, Cui Z, Wu H. RNA interference-mediated silencing of eukaryotic translation initiation factor 3 , subunit $B$ (EIF3B) gene expression inhibits proliferation of colon cancer cells. World J Surg Oncol 2012; 10: 119.

14. Wang H, Ru Y, Sanchez-Carbayo M, Wang X, Kieft JS, Theodorescu D. Translation initiation factor elF3b expression in human cancer and its role in tumor growth and lung colonization. Clin Cancer Res 2013; 19: 2850-2860.

15. Grzmil M, Rzymski T, Milani M, Harris AL, Capper RG, Saunders NJ et al. An oncogenic role of elF3e/INT6 in human breast cancer. Oncogene 2010; 29: 4080-4089.

16. Cappuzzo F, Varella-Garcia M, Rossi E, Gajapathy S, Valente M, Drabkin H et al. MYC and EIF3H coamplification significantly improve response and survival of non-small cell lung cancer patients (NSCLC) treated with gefitinib. $J$ Thoracic Oncol 2009; 4: 472-478.

17. Saramaki O, Willi N, Bratt O, Gasser TC, Koivisto P, Nupponen NN et al. Amplification of EIF3S3 gene is associated with advanced stage in prostate cancer. Am J Pathol 2001; 159: 2089-2094.

18. Sudo H, Tsuji AB, Sugyo A, Kohda M, Sogawa C, Yoshida $C$ et al. Knockdown of COPA, identified by loss-of-function screen, induces apoptosis and suppresses tumor growth in mesothelioma mouse model. Genomics 2010; 95: 210-216.

19. Sun Y, Yang Y, Zeng S, Tan Y, Lu G, Lin G. Identification of proteins related to epigenetic regulation in the malignant transformation of aberrant karyotypic human embryonic stem cells by quantitative proteomics. PLOS ONE 2014; 9: e85823.

20. Lee AS, Kranzusch PJ, Doudna JA, Cate JH. elF3d is an mRNA cap-binding protein that is required for specialized translation initiation. Nature 2016; 536: 96-99.

21. Li H, Zhou F, Wang H, Lin D, Chen G, Zuo X et al. Knockdown of EIF3D suppresses proliferation of human melanoma cells through G2/M phase arrest. Biotechnol Appl Biochem 2015; 62: 615-620.

22. Fan Y, Guo Y. Knockdown of elF3D inhibits breast cancer cell proliferation and invasion through suppressing the Wnt/beta-catenin signaling pathway. Int J Clin Exp Pathol 2015; 8: 10420-10427.

23. Zhang F, Li M, Wu X, Hu Y, Cao Y, Wang X et al. 20(S)-ginsenoside Rg3 promotes senescence and apoptosis in gallbladder cancer cells via the p53 pathway. Drug Design Dev Ther 2015; 9: 3969-3987.

24. Penela P, Murga C, Ribas C, Lafarga V, Mayor F Jr. The complex G protein-coupled receptor kinase 2 (GRK2) interactome unveils new physiopathological targets. Br J Pharmacol 2010; 160: 821-832.

25. Vroon A, Heijnen CJ, Lombardi MS, Cobelens PM, Mayor F Jr, Caron MG et al. Reduced GRK2 level in T cells potentiates chemotaxis and signaling in response to CCL4. J Leukocyte Biol 2004; 75: 901-909.

26. Nogues L, Reglero C, Rivas V, Salcedo A, Lafarga V, Neves M et al. G protein-coupled receptor kinase 2 (GRK2) promotes breast tumorigenesis through a HDAC6-Pin1 axis. EBioMedicine 2016; 13: 132-145.

27. Zhao S, Cao Y, Liu SB, Wang XA, Bao RF, Shu YJ et al. The E545K mutation of PIK3CA promotes gallbladder carcinoma progression through enhanced binding to EGFR. J Exp Clin Cancer Res 2016; 35: 97.

28. Chaffer CL, Weinberg RA. A perspective on cancer cell metastasis. Science 2011; 331: $1559-1564$.

29. Xia $\mathrm{H}$, Ooi LL, Hui KM. MicroRNA-216a/217-induced epithelial-mesenchymal transition targets PTEN and SMAD7 to promote drug resistance and recurrence of liver cancer. Hepatology 2013; 58: 629-641.

30. Zhang PF, Li KS, Shen YH, Gao PT, Dong ZR, Cai JB et al. Galectin-1 induces hepatocellular carcinoma EMT and sorafenib resistance by activating FAK/PI3K/AKT signaling. Cell Death Dis 2016; 7: e2201.

31. Wang X, Liang Z, Xu X, Li J, Zhu Y, Meng S et al. miR-148a-3p represses proliferation and EMT by establishing regulatory circuits between ERBB3/AKT2/c-myc and DNMT1 in bladder cancer. Cell Death Dis 2016; 7: e2503.

32. Canel M, Serrels A, Frame MC, Brunton VG. E-cadherin-integrin crosstalk in cancer invasion and metastasis. J Cell Sci 2013; 126(Pt 2): 393-401. 
33. Breier G, Grosser M, Rezaei M. Endothelial cadherins in cancer. Cell Tissue Res 2014; 355 523-527.

34. Lappano R, Maggiolini M. G protein-coupled receptors: novel targets for drug discovery in cancer. Nat Rev Drug Discov 2011; 10: 47-60.

35. Dorsam RT, Gutkind JS. G-protein-coupled receptors and cancer. Nat Rev Cancer 2007; 7 79-94.

36. Epstein RJ. The CXCL12-CXCR4 chemotactic pathway as a target of adjuvant breast cancer therapies. Nat Rev Cancer 2004; 4: 901-909.

37. Chakraborty PK, Zhang Y, Coomes AS, Kim WJ, Stupay R, Lynch LD et al. G proteincoupled receptor kinase GRK5 phosphorylates moesin and regulates metastasis in prostate cancer. Cancer Res 2014; 74: 3489-3500.

38. Zhou L, Wang MY, Liang ZY, Zhou WX, You L, Pan BJ et al. G-protein-coupled receptor kinase 2 in pancreatic cancer: clinicopathologic and prognostic significance. Hum Pathol 2016; 56: 171-177.

39. Billard MJ, Fitzhugh DJ, Parker JS, Brozowski JM, McGinnis MW, Timoshchenko RG et al. G protein coupled receptor kinase 3 regulates breast cancer migration, invasion, and metastasis. PLOS ONE 2016; 11: e0152856.

40. Metaye T, Levillain P, Kraimps JL, Perdrisot R. Immunohistochemical detection, regulation and antiproliferative function of G-protein-coupled receptor kinase 2 in thyroid carcinomas. J Endocrinol 2008; 198: 101-110.

41. Prowatke I, Devens F, Benner A, Grone EF, Mertens D, Grone HJ et al. Expression analysis of imbalanced genes in prostate carcinoma using tissue microarrays. Br J Cancer 2007; 96 : 82-88.

42. Penela $P$, Rivas V, Salcedo A, Mayor F Jr. G protein-coupled receptor kinase 2 (GRK2) modulation and cell cycle progression. Proc Natl Acad Sci USA 2010; 107: 1118-1123.

43. Ho J, Cocolakis E, Dumas VM, Posner BI, Laporte SA, Lebrun JJ. The G protein-coupled receptor kinase-2 is a TGFbeta-inducible antagonist of TGFbeta signal transduction. EMBO J 2005; 24: 3247-3258.

44. Penela P, Ribas C, Aymerich I, Eijkelkamp N, Barreiro O, Heijnen CJ et al. G protein-coupled receptor kinase 2 positively regulates epithelial cell migration. EMBO J 2008; 27: 1206-1218.

45. Salcedo A, Mayor F Jr, Penela P. Mdm2 is involved in the ubiquitination and degradation of G-protein-coupled receptor kinase 2. EMBO J 2006; 25: 4752-4762.

46. Ferguson SS. Phosphorylation-independent attenuation of GPCR signalling. Trends Pharmacol Sci 2007; 28: 173-179.
47. Ribas C, Penela P, Murga C, Salcedo A, Garcia-Hoz C, Jurado-Pueyo M et al. The G proteincoupled receptor kinase (GRK) interactome: role of GRKs in GPCR regulation and signaling. Biochim Biophys Acta 2007; 1768: 913-922.

48. Wan KF, Sambi BS, Tate R, Waters C, Pyne NJ. The inhibitory gamma subunit of the type 6 retinal CGMP phosphodiesterase functions to link c-Src and G-protein-coupled receptor kinase 2 in a signaling unit that regulates p42/p44 mitogen-activated protein kinase by epidermal growth factor. J Biol Chem 2003; 278: 18658-18663.

49. Yuan TL, Cantley LC. PI3K pathway alterations in cancer: variations on a theme. Oncogene 2008; 27: 5497-5510.

50. Wen W, Ding J, Sun W, Fu J, Chen Y, Wu K et al. Cyclin G1-mediated epithelialmesenchymal transition via phosphoinositide 3-kinase/Akt signaling facilitates liver cancer progression. Hepatology 2012; 55: 1787-1798.

51. Vier J, Groth M, Sochalska M, Kirschnek S. The anti-apoptotic Bcl-2 family protein A1/Bfl-1 regulates neutrophil survival and homeostasis and is controlled via PI3K and JAK/STAT signaling. Cell Death Dis 2016; 7: e2103.

52. Zhang F, Liu B, Wang Z, Yu XJ, Ni QX, Yang WT et al. A novel regulatory mechanism of Pim-3 kinase stability and its involvement in pancreatic cancer progression. Mol Cancer Res 2013; 11: 1508-1520.

(i) Cell Death and Disease is an open-access journal published by Nature Publishing Group. This work is licensed under a Creative Commons Attribution 4.0 International License. The images or other third party material in this article are included in the article's Creative Commons license, unless indicated otherwise in the credit line; if the material is not included under the Creative Commons license, users will need to obtain permission from the license holder to reproduce the material. To view a copy of this license, visit http://creativecommons.org/licenses/by/4.0/

(C) The Author(s) 2017

Supplementary Information accompanies this paper on Cell Death and Disease website (http://www.nature.com/cddis) 